SAND80-1184

Unlimited Release

$\mathrm{UC}-20 \mathrm{C}$

RETENTION, ISOTOPE EXCHANGE, AND THERMAL

RELEASE OF HYDROGEN IN CANDIDATE MATERIALS FOR TFTR

\title{
MASTER
}

W. R. Wampler, B. L. Doyle,

D. K. Brice, and S. T. Picraux

Prepared by Sandia Laboratories, Albuquerque, New Mexico 87185

and Livermore, California 94550 for the United States Department of

Energy under Contract DE-AC04-76DP00789.

August 1980

\section{Sandia National Laboratories}




\section{DISCLAIMER}

This report was prepared as an account of work sponsored by an agency of the United States Government. Neither the United States Government nor any agency Thereof, nor any of their employees, makes any warranty, express or implied, or assumes any legal liability or responsibility for the accuracy, completeness, or usefulness of any information, apparatus, product, or process disclosed, or represents that its use would not infringe privately owned rights. Reference herein to any specific commercial product, process, or service by trade name, trademark, manufacturer, or otherwise does not necessarily constitute or imply its endorsement, recommendation, or favoring by the United States Government or any agency thereof. The views and opinions of authors expressed herein do not necessarily state or reflect those of the United States Government or any agency thereof. 


\section{DISCLAIMER}

Portions of this document may be illegible in electronic image products. Images are produced from the best available original document. 
Issued by Sandia National Laboratories, operated for the United States Department of Energy by Sandia Corporation

\section{NOTICE}

This report was prepared as an account of work sponsored by the United States Government. Neither the United States nor the United States Department of Energy, nor any of their employees, nor any of their contractors, subcontractors, or their employees, makes any warranty, express of implied, or assumes any legal liability or responsibility for the accuracy, completeness, or usefulness of any information, apparatus, product or process disclosed, or represents that its use would not infringe on privately owned rights.

Printed in the United States of America

Available from

National 'l'echnical Information Service

U. S. Department of Commerce

5285 Port Royal Road

Springfield, VA 22161

Price: Printed Copy $\$ 4.50$; Microfiche $\$ 3.00$ 


\section{PAGES 1 to 2 WERE INTENTIONALLY LEFT BLANK}




\section{RETENTION, ISOTOPE EXCHANGE, AND THERMAL RELEASE OF HYDROGEN IN CANDIDATE MATERIALS FOR TFTR}

W. R. Wampler, B. L. Doyle,

D. K. Brice, and S. T. Picraux

\section{Introduction}

This report summarizes the results of hydrogen retention, hydrogen isotope exchange, and thermal release measurements for low-z coatings and claddings being evaluated as candidate materials for use in TFTR. The materials used in TFTR will be exposed to high fluxes of hydrogen, deuterium, and tritium ions and neutrals with energies in the range of. tens to thousands of electron volts: Retention and release of this hydrogen can grossly affect the plasma density, temperature, and isotopic composition during operation of TFTR. In addition, it is important to know how nuch tritium the materials will retain; and, therefore, processes which result in release of tritium from the materials, such as thermal detrapping and replacement by hydroyein or deuterium, nust be clearly understood. For these reasons the hydrogen retention, isotope exchange, and thermal release characteristics of the various materials must be taken into consideration in selecting a material suitable for use in TFTR. These processes were studied in a variety of materials by implanting hydrogen and deuterium at energies ( 0.6 to $1.5 \mathrm{keV} /$ atom) corresponding to typical particle energies in a tokamak environment. 
The materials studied included $\mathrm{TiC} \mathrm{TiB}_{2}, \mathrm{VB}_{2}, \mathrm{~B}_{4} \mathrm{C}, \mathrm{B}, \mathrm{Si}$, graphite, and the metals Ti, V, and $304 \mathrm{~L}$ stainless steel. The $\mathrm{TiC}$ and $\mathrm{TiB}_{2}$ were formed by chemical vapor deposition on a graphite substrate[1]. The $\mathrm{C} / \mathrm{Ti}$ ratio of the $\mathrm{TiC}$ was measured to be $1.0 \pm .05$, by ion backscattering analysis. The $\mathrm{Ti}$ and $\mathrm{V}$ were explosively bonded to copper substrates, and the $\mathrm{VB}_{2}$ was made by borodizing vanadium. Carbon (compression annealed pyrolytic graphite from Union Carbide and papyex graphite ribhon from tee Carbonol and single crystal silicon samples were included in the study as reference materials:

The hydrogen retention and isotope exchange behavior for these materials were studied by measuring the anount of $H$ or $D$ retained as a function of incident fluence using the $D\left({ }^{3} \mathrm{He}, \mathrm{p}\right)^{4} \mathrm{He}$ nuclear reaction analysis techniques for $D$ and $H\left({ }^{15} \mathrm{~N}, \alpha \gamma\right)$ profiling for H. [2]. In some cases the retained amounts of $H$ and $D$ were measured simultaneously using elastic recoil detection[3] with a $2.6 \mathrm{MeV}{ }^{4} \mathrm{He}$ analysis beam. These techniques give the total amount of $H$ or $D$ within $500 \mathrm{~nm}$ of the surface which is much thicker than the implant layer. The implants were done at room temperature. Incident fluxes in the range $1-3 \times 10^{14}$ atoms $/ \mathrm{cm}^{2} \mathrm{~s}$ were used which is low energy to avoid significant heating by the implant beam.

\section{Hydrogen Retention}

In the materials $\mathrm{TiC}, \mathrm{TiB}_{2}, \mathrm{VB}_{2}, \mathrm{~B}_{4} \mathrm{C}, \mathrm{B}, \mathrm{C}$, and $\mathrm{Si}$, it was found that at low fluences $\left(<3 \times 10^{16} / \mathrm{cm}^{2}\right.$ for $1.5 \mathrm{keV} /$ atom $)$ all the incident $\mathrm{H}$ or $\mathrm{D}$ was retained in the sample, apart from a small fraction (typically 5-10\%) which was kinematically reflected as shown in Fig. 1. As the incident fluence increased, the amount of $D$ retained eventually approached a saturation value which was 
in the range $1-3 \times 10^{16} \mathrm{D} / \mathrm{cm}^{2}$ for an implant energy of $1.5 \mathrm{keV} /$ ion. Depth profiling of $\mathrm{D}$ implanted in $\mathrm{C}[4], \mathrm{Si}[5], \mathrm{B}_{4} \mathrm{C}$, and $\mathrm{TiB}_{2}$ (this report) show that at low fluences hydrogen is retained at the end of its implant trajectory in these materials. The profile of hydrogen deposition in the materials is therefore determined by by the range and straggling of the hydrogen, which can be predicted theoretically $[5,6,7]$. As the incident fluence increases, a saturation hydrogen concentration is eventually reached in these materials. The retention behavior can be modeled[8] by assuming that hydrogen implanted into regions which have already reached saturation is not retained in the material. This type of behavior is illustrated in Fig. 2 , which shows calculated retention profiles (D concentration versus depth) for various fluences of $1.5 \mathrm{keV} D$ on graphite (solid lines). At high fluences where the material has reached saturation, the total amount of $\mathrm{D}$ retained depends on the saturation deuterium concentration for the material, and on the thickness of the saturated layer, and therefore on the energy of the incident deuterium. This can be seen in Fig. 3 which shows the areal density of $D$ retained in a graphite sample as a function of $D$ ion fluence for incident energies of 0.67 , 1.0 , and $1.5 \mathrm{keV}$. The solid lines are results of a calculation based on a model [8] which incorporates the deuterium deposition profile[7] and uses a saturation concentration of $0.53 \mathrm{H} / \mathrm{C}$ ratio. Th is figure illustrates the fact that a higher incident energy results in a higher areal density of retained hydrogen because of the greater thickness of the saturated layer.

The materials of Fig. I all behave similarly, but have different saturation concentrations, $\mathrm{N}_{\text {sat }}$. Using $\mathrm{N}_{\text {sat }}$ as the only adjustable parameter, the model described above was used to obtain the value of 
$\mathrm{N}_{\text {sat }}$ for each material from a fit to the data shown in Fig. 1. Table I summarizes the parameters used to model saturation in these materials. This table gives the saturation concentrations in units of $\mathrm{D} / \mathrm{cm}^{3}$ and $\mathrm{D} /$ host atom ratio, as well as the range and straggling parameters and the saturation areal densities for $1.5 \mathrm{keV} D$ in the various materials. The estimated accuracy of the saturation concentrations and areal densities are $\pm 15 \%$. Included in the table are the values for 316 stainless steel at $-120^{\circ} \mathrm{C}$ where hydrogen diffusion is suppressed[y].

The $\mathrm{D}$ retention data of Fig. 4 shows that $T i, V$, and stainless steel (at room temperature) behave differently from the other materials studied. The reason for this different behavior is that the hydrogen is mobile in these materials at room temperature. The diffusion coefficient for hydrogen in stainless steel at room temperature is $\sim 10^{-12} \mathrm{~cm}^{2} / \mathrm{s}$ with an activation energy of $\sim 0.6 \mathrm{eV}$ [10]. This means that in the time required for a measurement of retention, the diffusion length for the hydrogen is large compared to the implant depth. In this case, the observed retention will sensitively depend on the sample temperature, on the permeability of the surface, and the implant flux. Due to the high mobility of $D$ in stainless steel at room temperature, most of the $D$ is lost from the near surface region within several hours of the implant $[9,10]$.

The rate at which hydrogen implanted in stainless steel escapes was found to depend on the condition of the surface. The $304 \mathrm{SS}$ sample of Fig. 4 was electropolished prior to implantation. After an incident fluence of $\sim 3 \times 10^{18} \mathrm{D} / \mathrm{cm}^{2}$ at $1.5 \mathrm{keV}$, the analysis 
gave $\sim 8 \times 10^{16} \mathrm{D} / \mathrm{cm}^{2}$ in the near surface region. After 90 hours at room temperature, the analys is gave $1.5 \times 10^{16} \mathrm{D} / \mathrm{cm}^{2}$. These values are considerably higher than the retention previously observed for mechanically polished stainless steel samples[10]. This suggests the presence of a permeation barrier on the surface of the electropolished samples.

Hydrogen retention behavior in $\mathrm{Ti}$ and $\mathrm{V}$ is different from stainless steel because of the exothermic heat of solution of hydrogen in these materials and the tendency to form a hydride phase. Figure 4 shows that for 1.5 'keV Dimplanted'in $T i$ "and $v ;$ most of the $D$ is not retained in the first $500 \mathrm{~nm}$ probed by the nuclear reaction analysis. However, gas re-emission measurements [10] show that $\mathrm{D}$ implanted in $\mathrm{Ti}$ or $\mathrm{V}$ at room temperature is totally retained in the material (apart from the kinematically reflected fraction). Together these results show that most of the $D$ is diffusing into the bulk of the material beyond the $500 \mathrm{~nm}$ range of the nuclear reaction analysis. This means that in a tokamak environment these materials would retain large amounts of hydrogen isotopes. This would be undesirable in a tritium fueled machine.

\section{Isotope Exchange}

From the tritium inventory standpoint, it is important to know if tritium retained in a material can be recovered. In the materials which exhibit saturation behavior (TiC, TiB, $\mathrm{VB}_{2}$, $\left.\mathrm{B}_{4} \mathrm{C}, \mathrm{B}, \mathrm{C}, \mathrm{Si}\right)$, this can be done by replacing the tritium with hydrogen or deuterium. To characterize the isotope exchange behavior, we have implanted samples of the candidate materials 
with $\mathrm{D}$ (or $\mathrm{H}$ ) to saturation and then switched the implant ion to $H(o r ~ D)$ and monitored the $D$. and $H$ content of the samples as the second isotope displaced the first.

Figure 5 shows a composite of the isotope exchange curves for $\mathrm{TiC}, \mathrm{TiB}_{2}, \mathrm{VB}_{2}, \mathrm{~B}, \mathrm{C}$, and $\mathrm{Si}$. The dots and circles show the measured amounts of $\mathrm{D}$ and $\mathrm{H}$, respectively, retained in the samples versus $H+D$ fluence. The break in the curves occurs where the implant was switched from $D$ to $H$. The data for $B, T i, C, V B=1$, and $\mathrm{TiB}_{2}$ were taken using nuclear reaction analysis (NRA). The data shown for pyrolytic graphite and silicon were obtained using elastic recoil analysis which has the advantage of giving the amount of retained $\mathrm{H}$ as well as $\mathrm{D}$. Similar measurements on $\mathrm{C}$ and Si using NRA gave the same results within experimental uncertainty. Also, no difference in the saturation or exchange behavior was found between pyrolytic graphite and Papyex. It can be seen that the exchange behavior is similar in all of these materials:

To describe the hydrogen isotope exchange behavior we have developed a new model which treats the exchange difforontially in depth. The model uses the $H$ and $D$ deposition profiles which can be obtained from standard transport theory $[6,7]$ and the saturation concentrations for the various materials determined from the retention measurements described in the previous section (see Table 1). These saturation concentrations can also be directly measured using high resolution depth profiling techniques. No additional free parameters are required by this model to describe the exchange behavior. This model assumes that for every $H, D$, or $T$ atom which comes to the end of its trajectory in a region of the 
material which is saturated, one $H, D$, or $T$ is lost from the material so that the local $(H+D+T) /$ host atom ratio never exceeds the saturation concentration. Also the model assumes that local mixing of the hydrogen isotopes occurs. In other words that the probability of the displaced atom being $H, D$, or $T$ is given by the ratio of the local $H, D$, or $T$ concentrations to the saturation concentration respectively. Incident $\mathrm{H}, \mathrm{D}$, or $\mathrm{T}$ atoms stopping in regions which are below saturation are retained.

The calculated profiles for $D$ retention in graphite shown in Fig. 2 illustrate how D initially implanted to saturation is replaced by subsequent. implantation with $H$. The exchange proceeds most rapidly at a depth corresponding to the peak in the deposition of the $H$, but proceeds more slowly in the wings of the profile. Just after.switching isotopes the exchange rate is close to $1: 1$ (one D lost for every incident $H$ ) because. the $D$ concentration is initially much larger than the Il concentration at all depths. As the replacement proceeds, however, the exchange rate deceases because more and more of the displaced atoms are $H$ rather than D. The total amount of $D$ and $H$ in the sample can be calculated by integrating over depth. Plotting this as a function of the total incident $H+D$ fluence gives theoretical isotope exchange curves which are compared to the data in Fig. 5. The agreement between the data and the model is within the experimental uncertainty in all cases. 
In order to check that our isotope exchange model has the correct dependence on the incident particle energy, isotope exchange measurements were made in graphite using different incident energies for the $\mathrm{H}$ and $\mathrm{D}$. This changes the overlap between the depth profiles of the two isotopes and thereby affects the exchange behavior. When the $H$ and $D$ are both implanted at $1.5 \mathrm{keV}$ (Fig. 6a), the $\mathrm{H}$ and $\mathrm{D}$ profiles overlap very closely. The morel show that in this case the $D$ on the deep side of the profile is hard to replace because fewer $\mathrm{H}$ atoms stop at this depth than at the peak. Decreasing the $\mathrm{H}$ energy to $1 \mathrm{keV}$ (Fig. 6h) shiftei the H profile toward the surface such that more of the $D$ on the deep side of the profile remains in the sample. Decreasing the initially implanted $D$ energy to $\mathrm{l}$ keV (Fig. 6C) shifts the D profile toward the surface such that the deeper $D$ is more easily replaced by the $H$. The good agreement between the data (dots) and the model (1 ines) indicates that the model contains the correct dependence on the incident particle energy.

We have also measured the isotope exchange in graphite and Si both with $H$ and with $D$ as the initially implanted 1sotope. The exchange behavior in both cases was similar. This demonstrates that there are no unexpected isotope effects and supports the expectation that replacement of tritium would behave in a similar way.

\section{Thermal Release}

In addition to isotopic replacement by implantation, hydrogen isotopes can also be released by heating. The practicality of heating as a method to release tritium frull tokamak components depends on the nature of the component and the temperature that 
is required. On the other hand, some components such as limiters may reach high temperatures during routine operation of the machine: For these reasons, it is of interest to survey the thermal release properties of the candidate materials. Extensive studies of thermal release have been done by $K$. L. Wilson and A. E. Pontau at Sandia Laboratories in Livermore by measuring gas re-emission during ramp heating. These studies are described in a separate report $[10]$.

To determine whether thermal release is preceded by diffusion into the bulk of the sample as was found to be the case for $\mathrm{T} i$ and $\mathrm{V}$ at room temperature, nuclear reaction analysis can be used to determine the effect of heating on the near surface $H$ or $D$ content and depth profiles. Figure 7 shows the results of such measure-

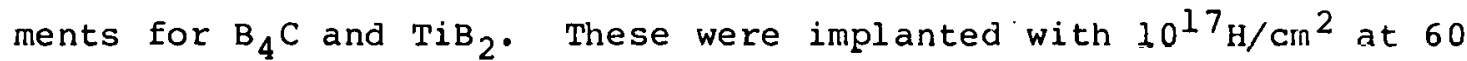
and $40 \mathrm{keV}$ respectively. The $\mathrm{H}$ profiles were measured using the $\mathrm{H}\left({ }^{19} \mathrm{~F}, \alpha \dot{\gamma}\right)$ reaction after annealing the samples for 20 minute intervals at successively higher temperatures. Most of the $\mathrm{H}$ was released after annealing at $400^{\circ} \mathrm{C}$ for $\mathrm{TiB}_{2}$ and $700^{\circ} \mathrm{C}$ for $\mathrm{B}_{4} \mathrm{C}$. The fact that the depth profiles do not significantly broaden shows that the rate limiting process in the release is detrapping rather than diffusion through the bulk material: previous studies[4] have shown a similar behavior for the release of D implanted in graphite. Table II'summarizes the approximate temperature range over which thermal release of $H$ or $D$ has been observed in the various candidate naterials.

5. Hydrogen Retention and Isotope Exchange in a Tokamak Environment In order to estimate hydrogen retention and isotope exchange 
in a tokamak environment, it is necessary to include the effects of a distribution of energies and angles of incidence for the hydrogen. Our model for saturation and isotope exchange can easily include these effects by using the hydrogen depth profile for the desired energy and angular distributions. In contrast to previous models for isotope exchange $[9,11]$, the dependence on implant energy in our model is all contained in the deposition profiles. Experimental veritication chat uur mudel contains the correct energy dependence is given in Figs. 6 and 8 . Figure 8 shows data from measurements by Blewer et al [4] of saturation with $D$ and replacement by $\mathrm{H}$ in 316 stainless steel at $-120^{\circ} \mathrm{C}$ for incident energies between 1 and $14 \mathrm{keV}$. The solid 1 ine shows the behavior predicted by our model using a saturation concentration of $1.0(H+D) /$ metal atom ratio. In all cases the agreement is excellent.

If we assume that a surface in a tokamak will be exposed to incident hydrogen with a Maxwellian velocity distribution the retention and exchange behavior can be calculated. Figure 9 shows the retention behavior expected under these conditions for $\mathrm{TiB}_{2}$, and $\mathrm{TiC}$, for a range of Maxwellian temperatures. This is plotted in Fig. 10 as the areal density of $D$ retained after an incident fluence of $10^{20} \mathrm{D} / \mathrm{cm}^{2}$ as a. function of the characteristic particle temperature. The right hand scale gives the equilivant activity in $\mathrm{Ci} / \mathrm{m}^{2}$ if the retained atoms ware all. tritium. From this, one can estimate an upper limit for the tritium inventory in these materials. For example, if one assumes a plasma edge 
temperature of $\mathrm{l} \mathrm{keV}$ for TFTR, then after an incident fluence of $10^{20} \mathrm{~T} / \mathrm{cm}^{2}$, a $10 \%$ coverage of the internal surface of TFTR $\left(\sim 10 \mathrm{~m}^{2}\right)$ by $\mathrm{TiC}$ could retain as much as $\sim 1000 \mathrm{Ci}$ if the retained atoms were all $T$. This is less than the $2300 \mathrm{Ci}$ allowed $T$ inventory in TFTR in readily releasable form.

Figure 11 shows the calculated isotope exchange behavior for $T$ being replaced by $D$ in $T i C$ for the case of a Maxwellian velocity distribution. This illustrates the feature that the high energy tail of the Maxwellian distribution leads to a sustained gradual build-up of retained $T$ to greater depths and that recovery of this deep component by isotope exchange will require high $D$ fluences. If the initial $T$ fluence is increased by an order of magnitude, then about an order of magnitude higher $D$ fiuence is also needed to reduce the $T$ content to a given level. The efficiency of the $T$ recovery $c a n$ be greatly enhanced by using $D$ which is more energetic than the T. This can be seen in Fig. 12 which shows a calculation to model the replacement of $\mathrm{T}$ from $\mathrm{TiC}$ which is initially exposed to a $\mathrm{T}$ plasina with $\mathrm{kT}=200 \mathrm{eV}$ to a fluence of $10^{18} \mathrm{~T} / \mathrm{cm}^{2}$ followed by exposure to; 1) a D plasma with $k T=200 \mathrm{eV}$, or 2) a D plasma with $k \mathrm{~T}=400 \mathrm{eV}$. Finally, Table III gives the amount of retained $D$ measured in several materials after. exposure to high power discharges in PLT, including some of the coating materials and a piece cut from a graphite limiter. The inrident $D$ fluence to these samples was hiqh enough to saturate the near surface. The anount of $\mathrm{D}$ retained is consistent with the retention characteristics of the materials, and the energy and flux of $D$ at the plasma edge 
determined from probe studies[12].

\section{Conclusions}

In summary, our results show that hydrogen retention behavior is qualitatively similar for the materials $\mathrm{TiC}, \mathrm{TiB}_{2}, \mathrm{VB}_{2}, \mathrm{~B}_{4} \mathrm{C}, \mathrm{B}$, Si, and graphite. The amount of hydrogen retained depends on the implant depth, and hence on the energy of the incident hydrogen, and on the saturation concentration for the material. The saturation concentrations for these materials (at room temperature) was found to he in the range 0.1 .6 to 0.57 hydrogen/livsl aluil tatclu. ihe areal density of hydrogen retained after saturation with a given incident energy was lower in $\mathrm{TiC}_{1} \mathrm{IiB}_{2}$, and $\mathrm{VB}_{2}$ by about a factor of 3 than in $\mathrm{B}, \mathrm{B}_{4} \mathrm{C}$, and graphite. We have also found that hydrogen isotopes in these materials can be replaced by subsequent implantation with a different isotopic specie. This indicates that recovery of tritium from these materials by replacement with hydrogen or deuterium should be feasible. The model we have developed to describe this process agrees very well, with the data and provides for the first time a way to predict retention and exchange behavior in a tokamak environment. This is important not only from the tritium inventory standpoint but also for modeling effects of recycling at the wall on the isotopic composition of the plasma during a discharge.

The retention and exchange behavior of hydrogen in ' $\mathrm{l}$ 'i and $V$ is different because of the mobility and exothermic heat of solution ot hydrogen in these materials. In a tritium fueled tokamak, these materials could retain much larger amounts of tritium, and recovery by isotope exchange does not appear to be practical. Tritium release from these materials would require heating to $\sim 300$ to $500^{\circ} \mathrm{C}$. 


\section{References}

1. D. M. Mattox, Thin Sold Films 63, (1979) 213.

2. J.F. Ziegler, C.P. Wu, P. Williams, C.W. White, B. Terreault, B.M.U. Scherzer, R.L. Schulte, E.J. Schneid, C.W. Magee, E. Ligeon, J. I,Ecuyer, W.A. Lanford, F.K. Kuehne, E.A. Kamykowski, W.O. Hofer, A. Guivarc'h, C.H. Filleux, V.R. Deline, C.A. Evans, Jr., B.L. Cohen, G.J. Clark, W.K. Chu, C. Brassard, R.S. Blewer, R. Behrisch, B.R. Appleton; and D. D. Allred, Nuclear Instruments and Methods 149 (1978) 19-39.

3. B. L. Doyle, P. S. Peercy, Appl. Phs. Lett. 34 (1979) 811.

4. R. A. Langley, R. S. Blewer, and J. Roth, J. Nucl. Mat. $\underline{76}$, 77 (1978) 313.

5. C. W. Magee, S. A. Cohen, D. E. Voss,....... Brice, Nucl.: Inst." Meth. $168(1980) \cdots 383$.

6. J. Biersack, L. G. Haggmark, Nụcl. Inst. \& Methods, in press.

7. Most of the range profiles used in the calculations were calculated using the TRIM code[6]. These profiles were found to differ only slightly from those obtained using the spherical gaussian with image gaussian model (S. A. Cohen, G. M. McCracken, J. Nucl. Mat. 84, (1979) 157) with projected range and straggling parameters from Brice (D. K. Brice, Radiation Effects $\underline{13}$ (1972) 215).

8. B. L. Doyle, W. R. Wampler, D. K. Brice, and S. T. Picraux, Proceedings of the Fourth International Conference on Plasma Surface Interactions in Controlled Fusion Devices, GarmischPartenkirchen, April 1980.

9. R. S. Blewer, R. Behrisch, B. M. U. Scherzer, and R. Schulz, J. Nucl. Mat. $\underline{76}, \underline{77}$ (1978) 305:

10. K. L. Wilson and A. E. Pontau, Sandia National Laboratories Report, unc: $8347 / 1,5-22-80$.

11. E. S. Hotston, J. Nucl. Mat. 88 (1980) 279.

12. G. M. McCracken, S. A. Cohen, H. F. Dylla, C. W. Magee, S. T. Picraux, S. M. Rossnagel, Proceedings of the 9 th European Conference on Controlled Fusion and Plasma Physics, Oxford, Sept. 1979. 


\section{Figure Captions}

1. Retention curves measured by nuclear reaction analys is for $1.5 \mathrm{keV} D$ incident on several low $z$ target materials.

2. Calculated $D$ retention profiles for various incident $D$ fluences showing saturation for the higher fluences. The dashed lines show the $D$ profiles after partial replaceinent by $\mathrm{H}$.

3. Calculated (solid lines) and experimental (symbols) retention of $\mathrm{D}$ implanted in carbon for different incident energies.

4. Retention curves measured by nuclear reaction analys is fnr 1,5 k, $\mathrm{V} D$ inoident on $\mathrm{Ti}, \mathrm{V}$, aild 304 stalnless steel.

5. Calculated (solid and dashed lines) and experimentally measured (dots and circles) saturation and isotope exchange behavior for various low 2 materials implanted with $3 \mathrm{keV}$ $\mathrm{D}_{2}^{+}$followed by replacement with $3 \mathrm{keV} \mathrm{H}_{2}^{+}$.

6. This figure shows the effect on isotope exchange of using different energies for the initial (D) and replacing (H) ion species.

7. Retention and depth profiles for $\mathrm{H}$ in $\mathrm{B}_{4} \mathrm{C}$ and $\mathrm{TiB} \mathrm{B}_{2}$ after annealing for 20 minute intervals at successively higher temperatures.

8. Saturation and isotope exchange in 316 stainless steel at $120^{\circ} \mathrm{C}$, for different incident energies. The symbols show the data measured by Blewer et al [7], and the solid lines are the prediction of our model using $\mathrm{N}_{\text {sat }}=1.0$.

9. Calculated $D$ retention versus incident fluence for isotropic and Maxwellian angular and energy distributlons and different ion temperatures in $\mathrm{TiC}$ (a) and $\mathrm{TiB}_{2}$ (b).

10. Calculated $D$ retention in TiC, and $T i B_{2}$ versus plasma temperature for an incident fluence of $10^{20} \mathrm{v} / \mathrm{cm}^{2}$. The scale on the right shows the equivalent activity if the retainer atoms were all tritium.

11. Calculated isotope exchange behavior for replacement of $T$ by $D$ in TiC for Maxwellian velocity distributions with $k T=200 \mathrm{eV}$.

12. Calculated retention and exchange for TiC exposed to $T$ with $\mathrm{kT}_{\mathrm{T}}=200 \mathrm{eV}$ followed by $\mathrm{D}$ with $\mathrm{kT}=200 \mathrm{eV}$ or $\mathrm{D}$ with $\mathrm{kT}=$ $400 \mathrm{eV}$. 


\begin{tabular}{|c|c|c|c|c|c|}
\hline \multirow[b]{2}{*}{ Material } & \multicolumn{3}{|c|}{$1.5 \mathrm{keV}$ Deuterium } & \multicolumn{2}{|c|}{ Saturation Concentration } \\
\hline & $\begin{array}{c}\text { Range } \\
0 \\
(A)\end{array}$ & $\begin{array}{c}\text { Straggling } \\
(A)\end{array}$ & $\begin{array}{l}\text { Saturation } \\
110^{17} \mathrm{D} / \mathrm{cm}^{2}\end{array}$ & $\left(10^{22} \mathrm{D} / \mathrm{cm}^{3}\right)$ & $\begin{array}{l}\text { H/Host } \\
(\%)\end{array}$ \\
\hline c & 247 & 101 & 2.50. & 6.0 & 53 \\
\hline Si. & 335 & 161 & 1.91 & 2.5 & 50 \\
\hline B & 216 & 95 & 3. 40 & 5.9 & 45 \\
\hline$B_{4} C$ & 288 & 117 & 3.57 & 6.9 & 57 \\
\hline TiC & 183 & 91 & 1.22 & 2.5 & 26 \\
\hline$V B_{2}$. & .189 & 92 & 0.96 & 1.9 & 16 \\
\hline $\mathrm{TiB}_{2}$ & 208 & 102 & 1.00 & 1.8 . & 16 \\
\hline $316 \mathrm{SS}^{\circ}$ & 100 & 117 & 3.00 & 8.5 & 100 \\
\hline
\end{tabular}




\begin{tabular}{cc} 
Material & $\begin{array}{c}\text { Temperature Range } \\
\text { for H Release }\left(^{\circ} \mathrm{C}\right)\end{array}$ \\
\hline $\mathrm{C}$ & $350=550$ \\
$\mathrm{Si}$ & $300-600$ \\
$\mathrm{~B}$ & $100-525$ \\
$\mathrm{~B} 4 \mathrm{C}$ & $400-700$ \\
$\mathrm{TiC}$ & $100-600$ \\
$\mathrm{VB} 2$ & $100-500$ \\
$\mathrm{TiB} 2$ & $100-500$ \\
$316 \mathrm{SS}$ & -200 \\
$\mathrm{Ti}$ & $300-$ \\
$\mathrm{V}$ & $300-$ \\
\hline
\end{tabular}

TABLE 2. 
TA BLE III

DEUTERIUM RETAINED IN VARIOUS MATERIALS EXPOSED TO,DISCHARGES IN PLT,

\begin{tabular}{|c|c|c|}
\hline MATERIAL & $\begin{array}{l}\text { \# OF SHOTS } \\
\text { (PLASMA) }\end{array}$ & $\begin{array}{c}10^{16} \mathrm{D} / \mathrm{cm}^{2} \text { RETAINED } \\
10^{16} / \mathrm{cm}^{2}\end{array}$ \\
\hline$C(P R O B E)$ & $12 \mathrm{D}$ & $8-18$ \\
\hline C LIMITER & HUNDREDS $(H, D)$ & $10-30$ \\
\hline TIC & $14(D+H E)$ & 4.4 \\
\hline $\mathrm{T}_{\mathrm{IB}} \mathrm{B}_{2}$ & $14(\mathrm{D}+\mathrm{HE})$ & 3.9 \\
\hline v & $14\left(D+H_{E}\right)$ & 1.5 \\
\hline c & $14\left(D+H_{E}\right)$ & 9.4 \\
\hline
\end{tabular}




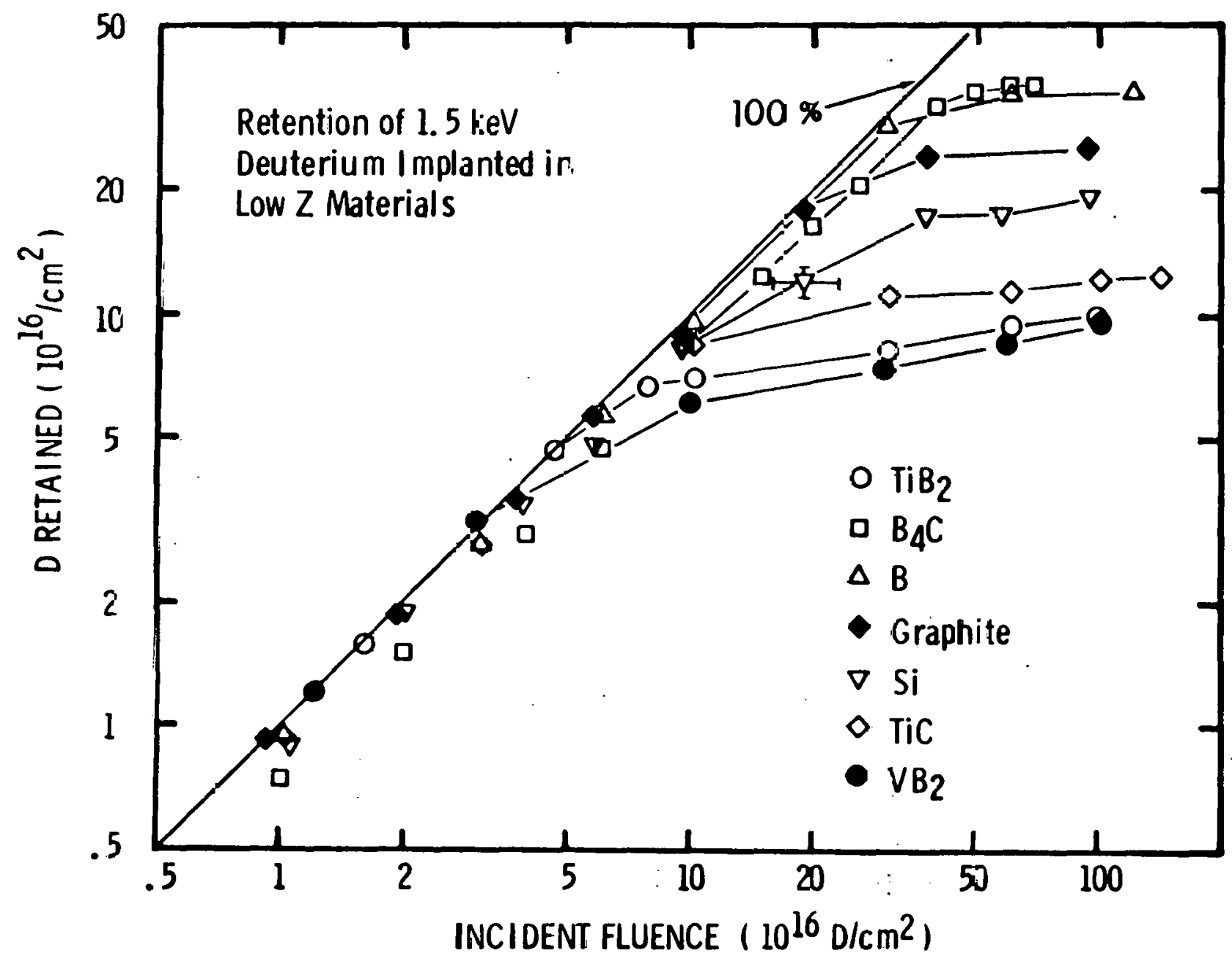




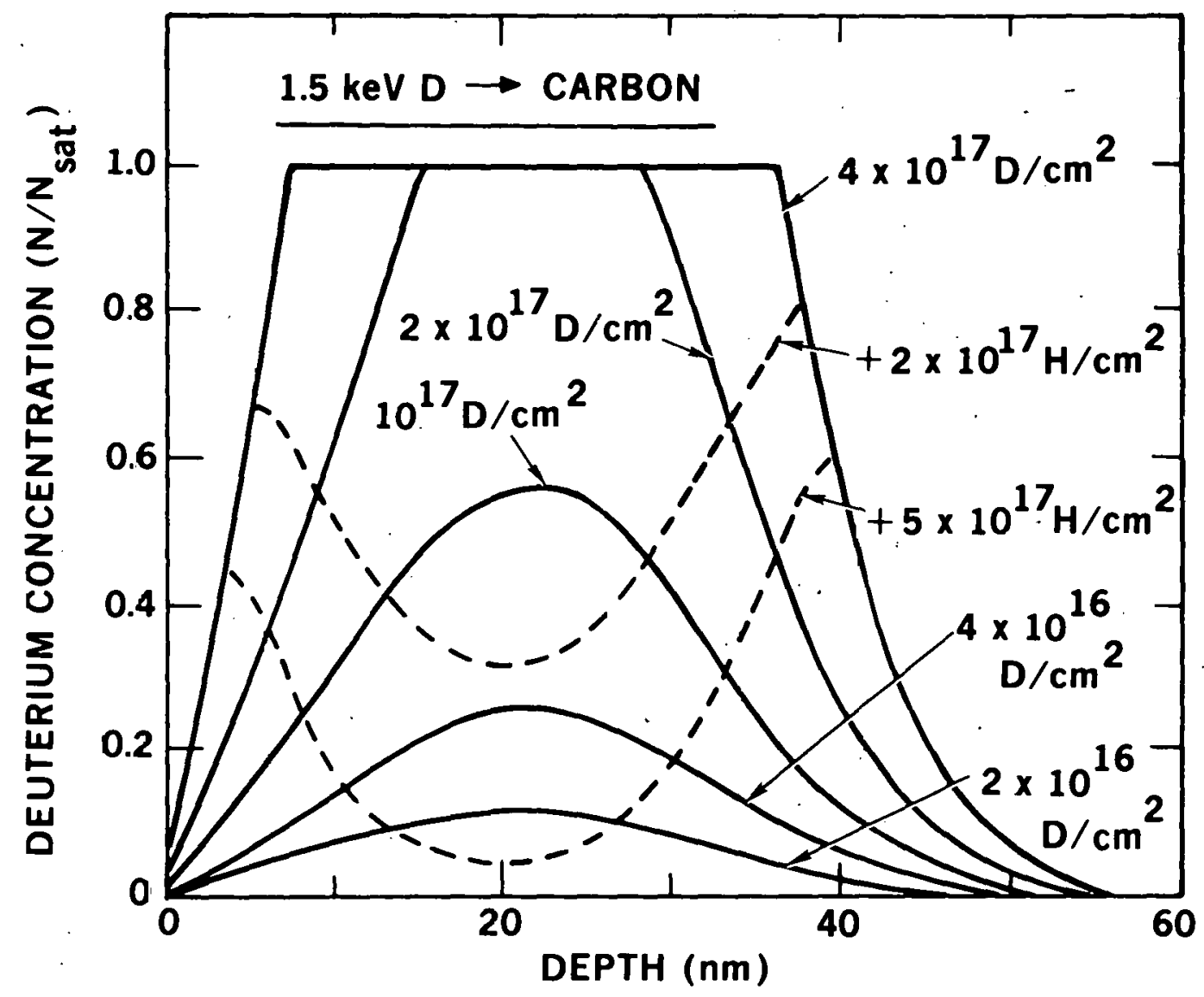




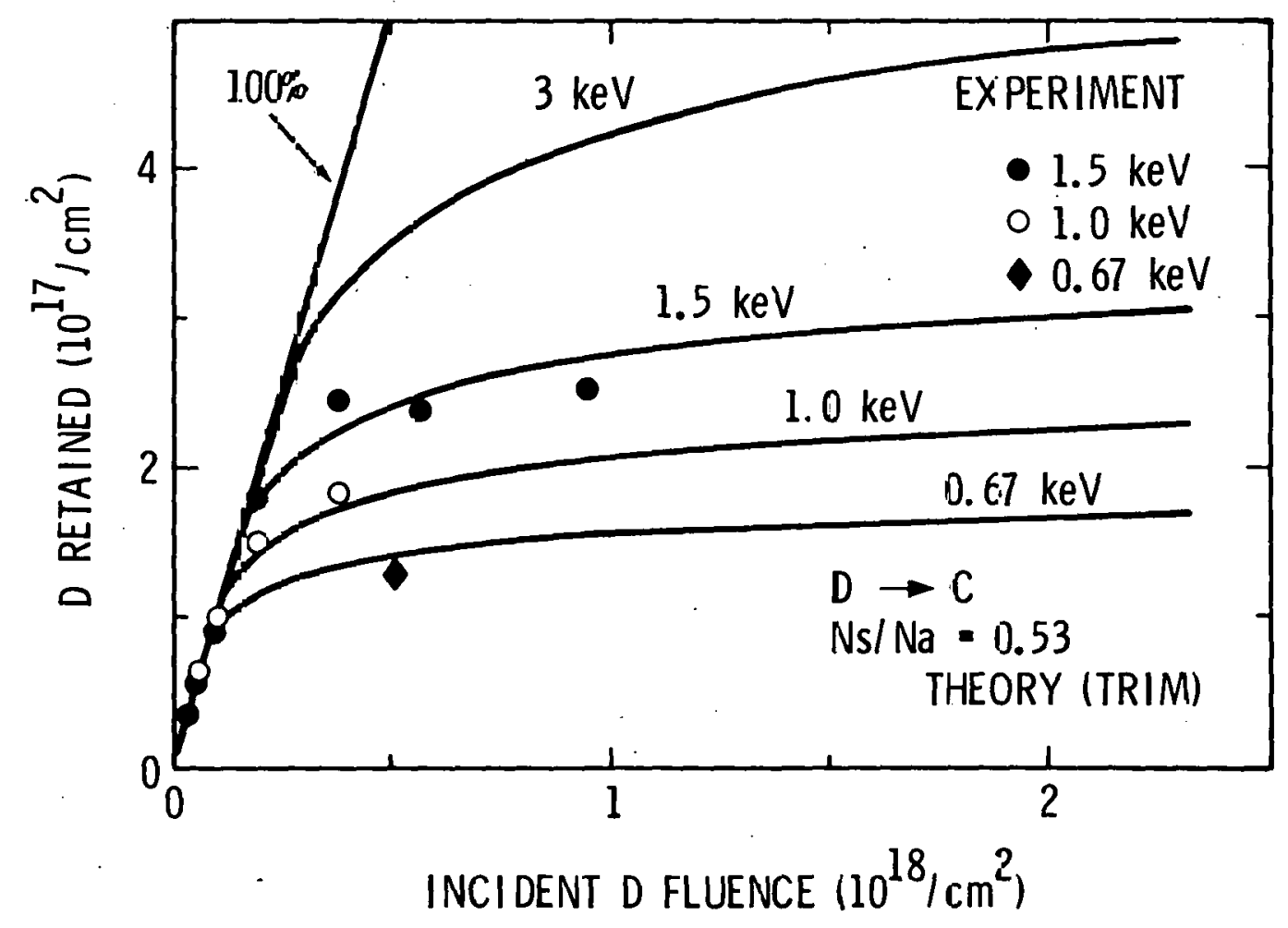




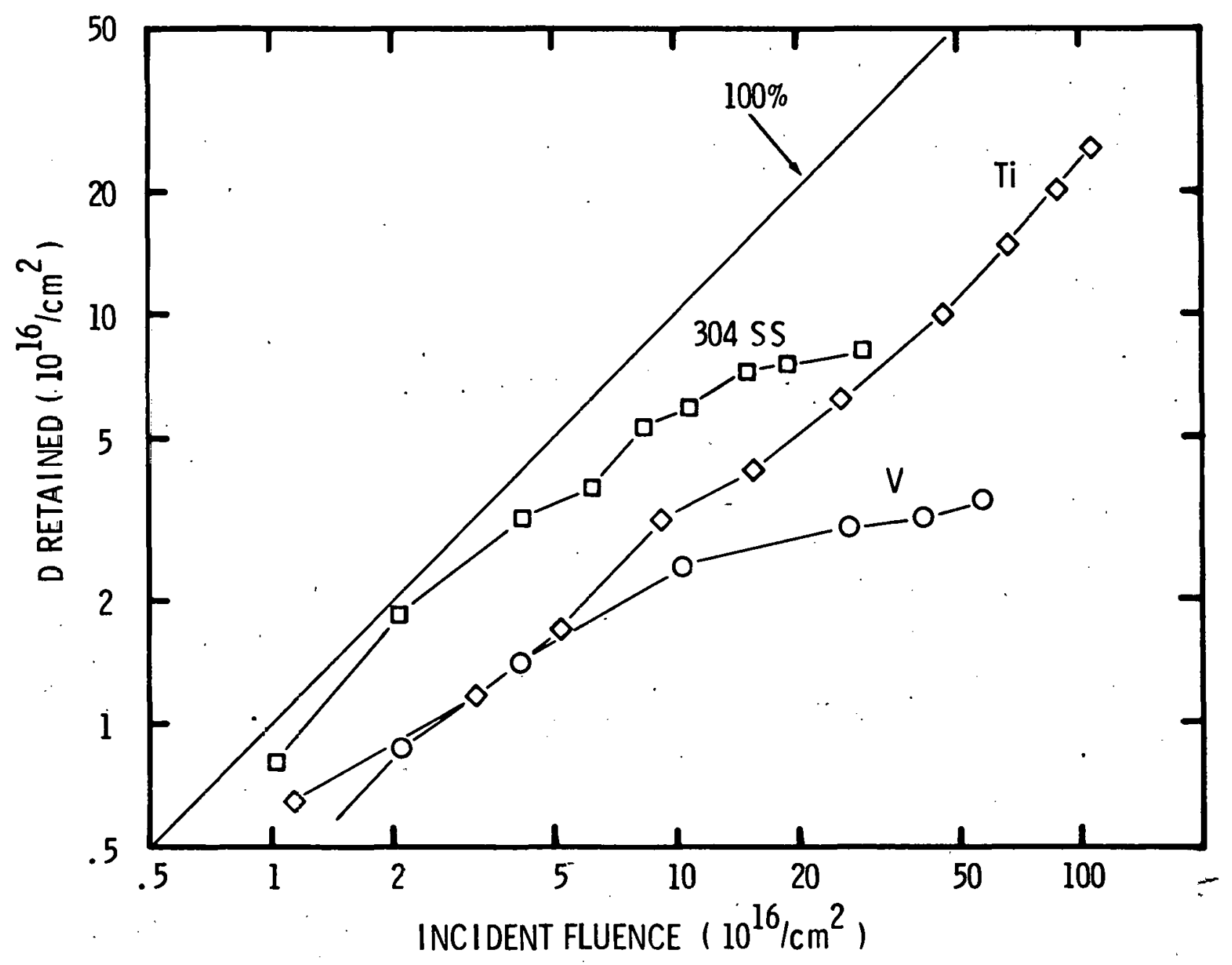




\section{LOW Z COATING MATERIALS}
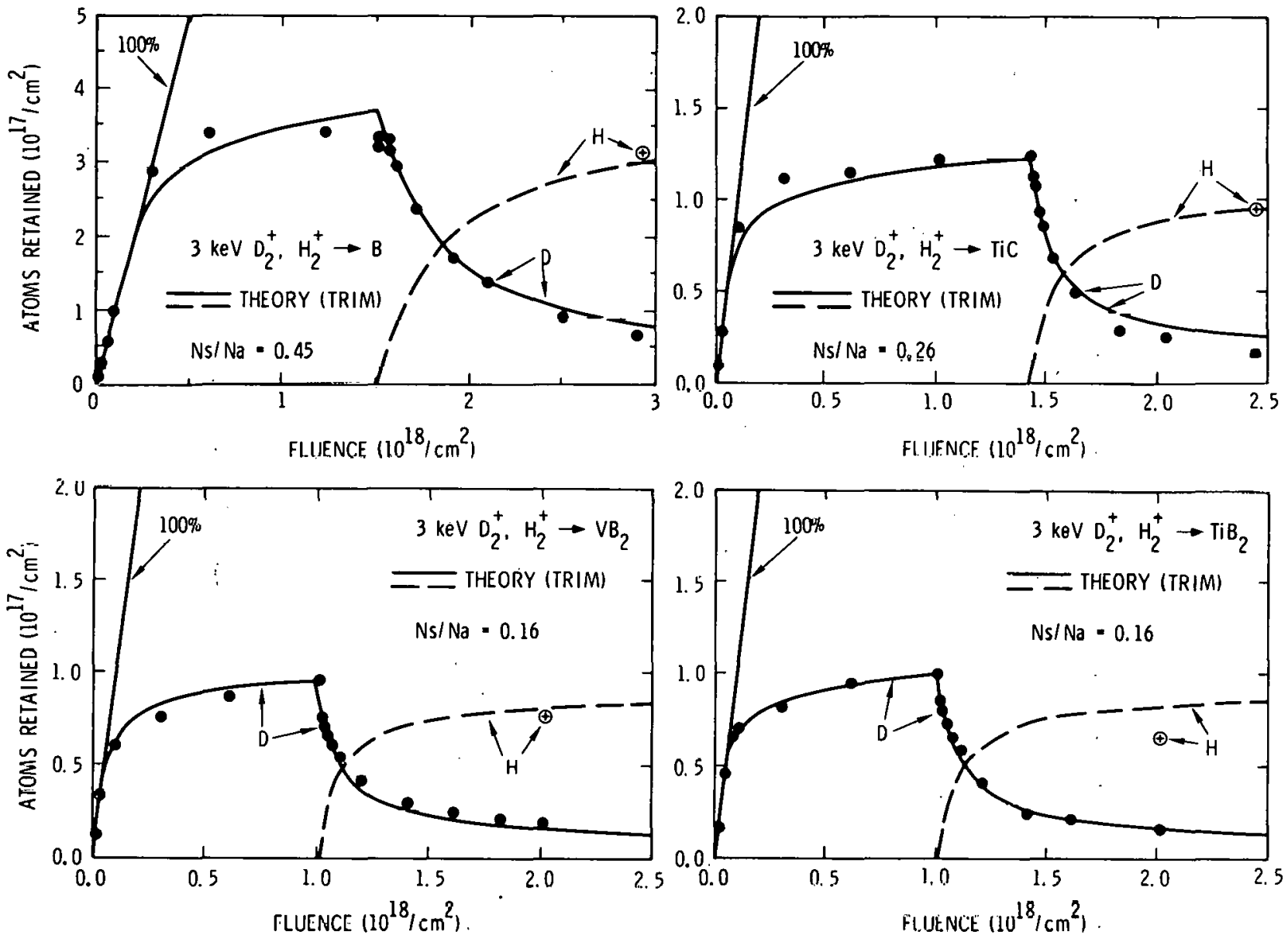

\section{CARBON AND SILICON}
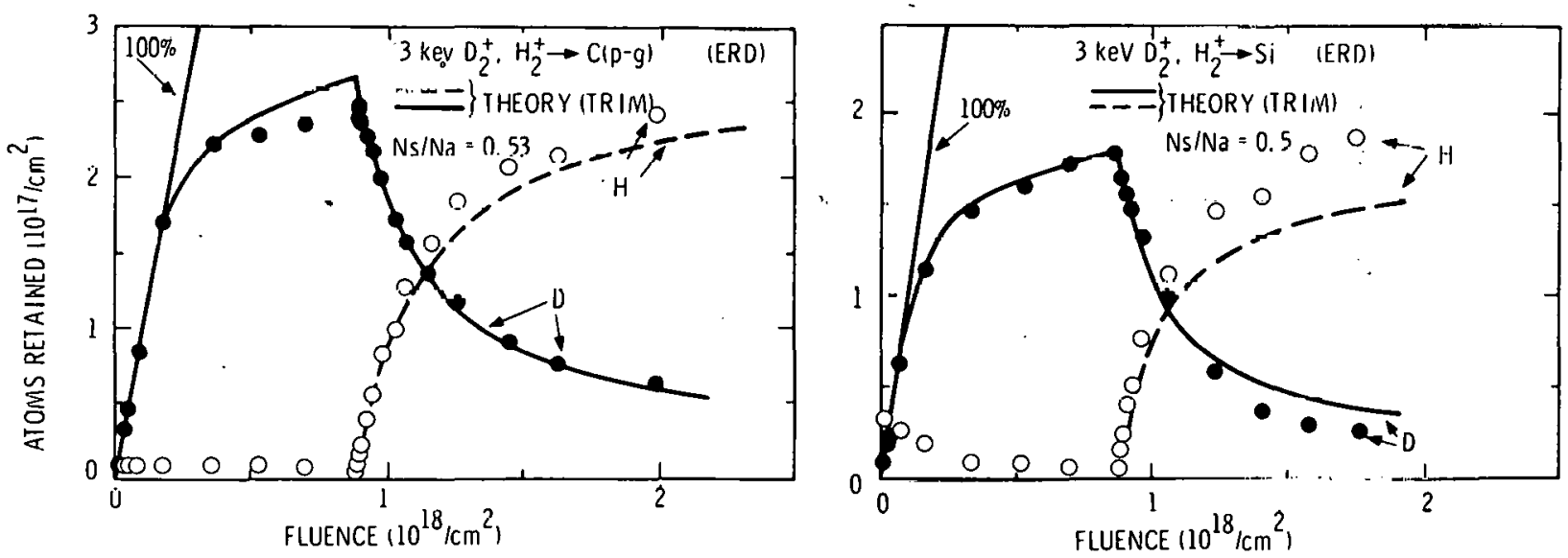

Figure 5 

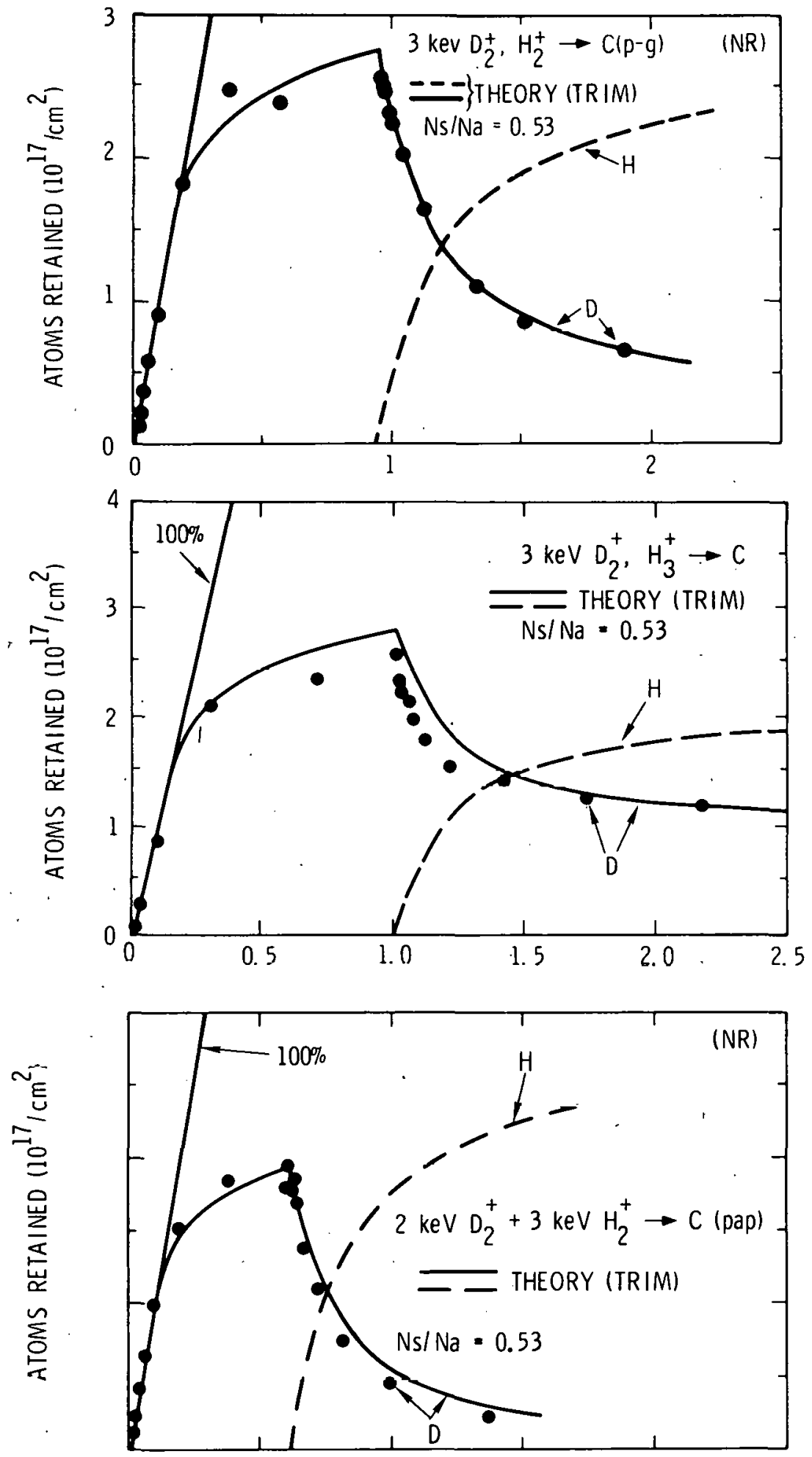

FLUENCE $\left(10^{18} / \mathrm{cm}^{2}\right)$

Figure 6 

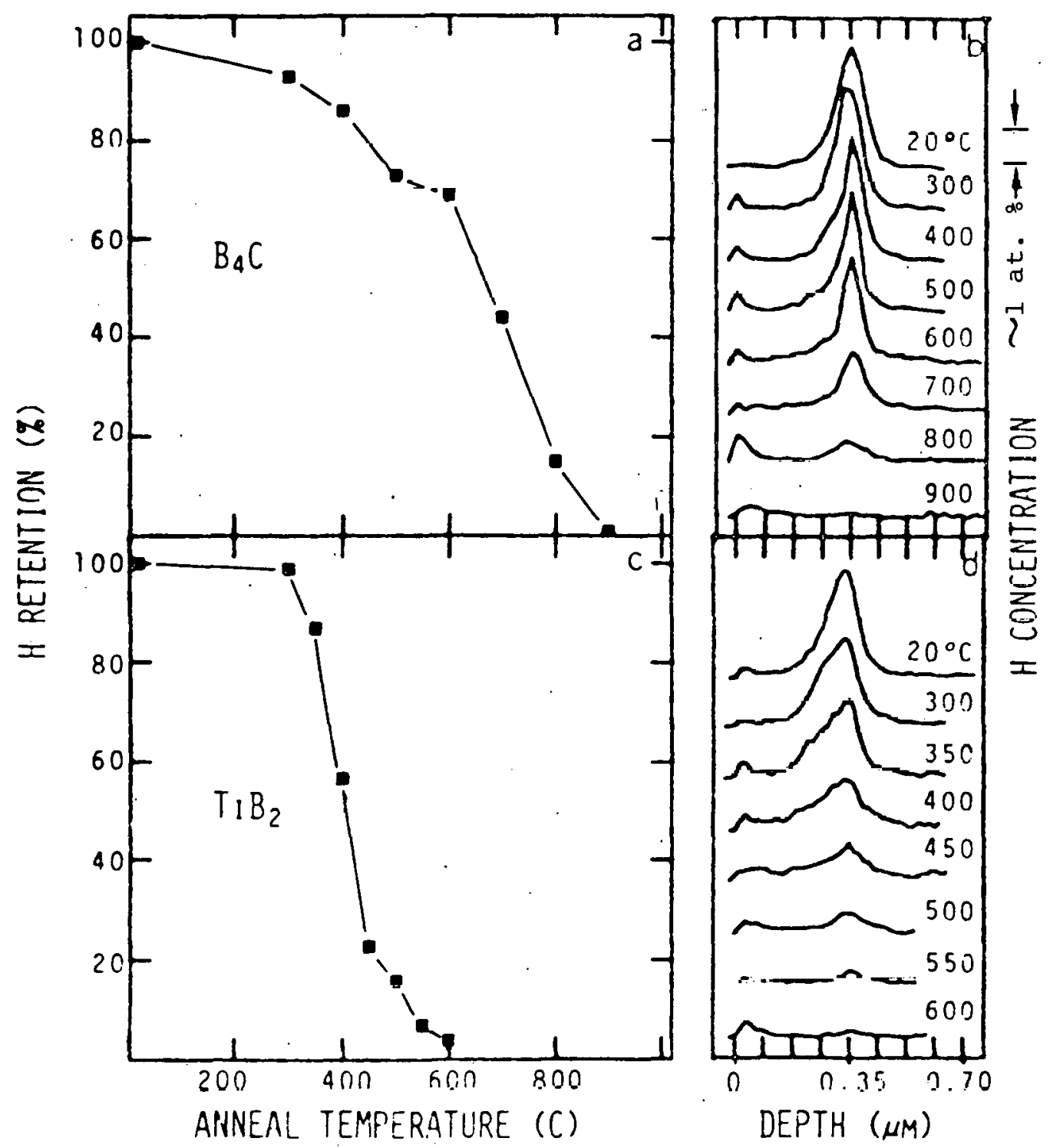

Figure 7 


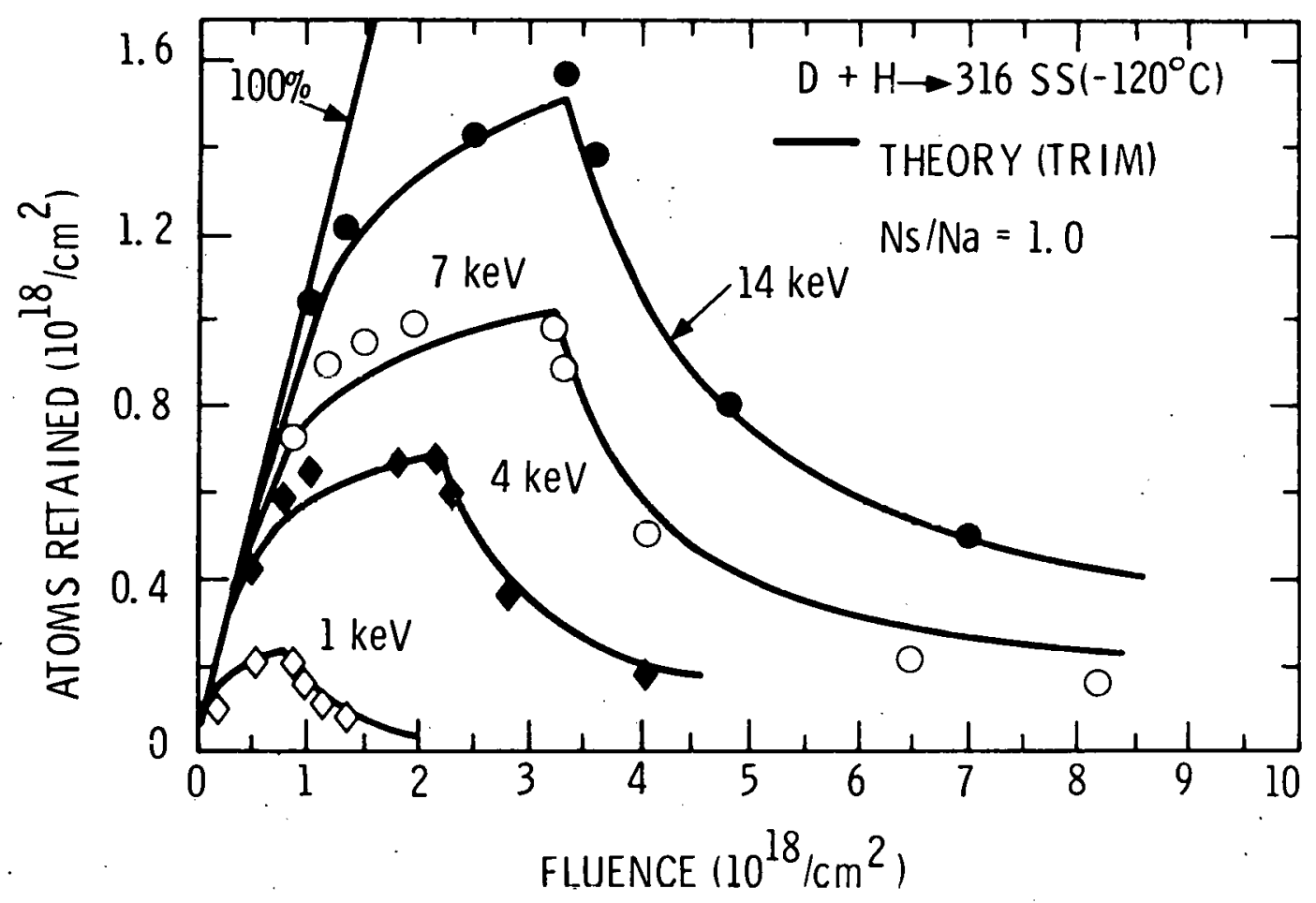

Figure 8 

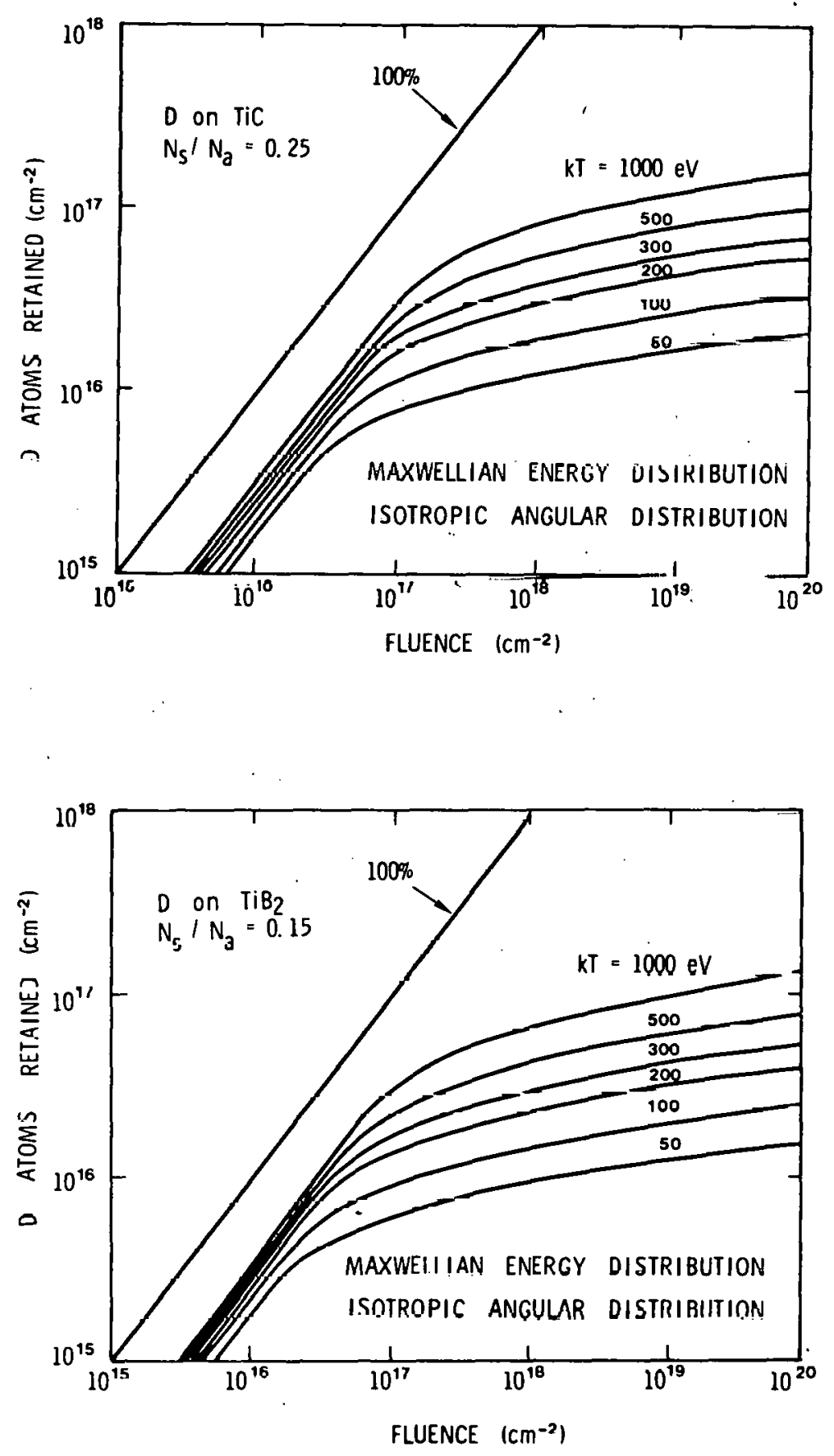

Figure 9 


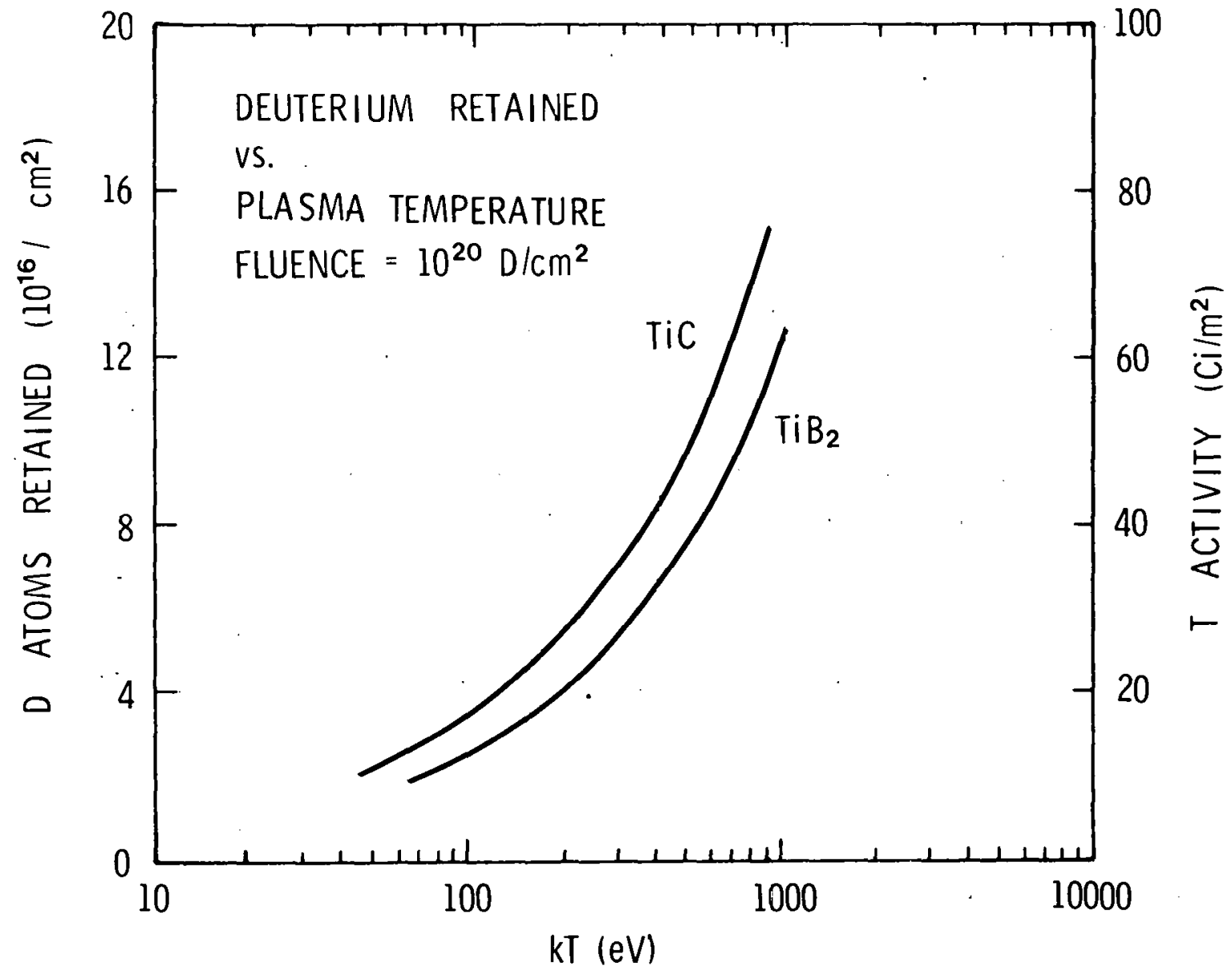




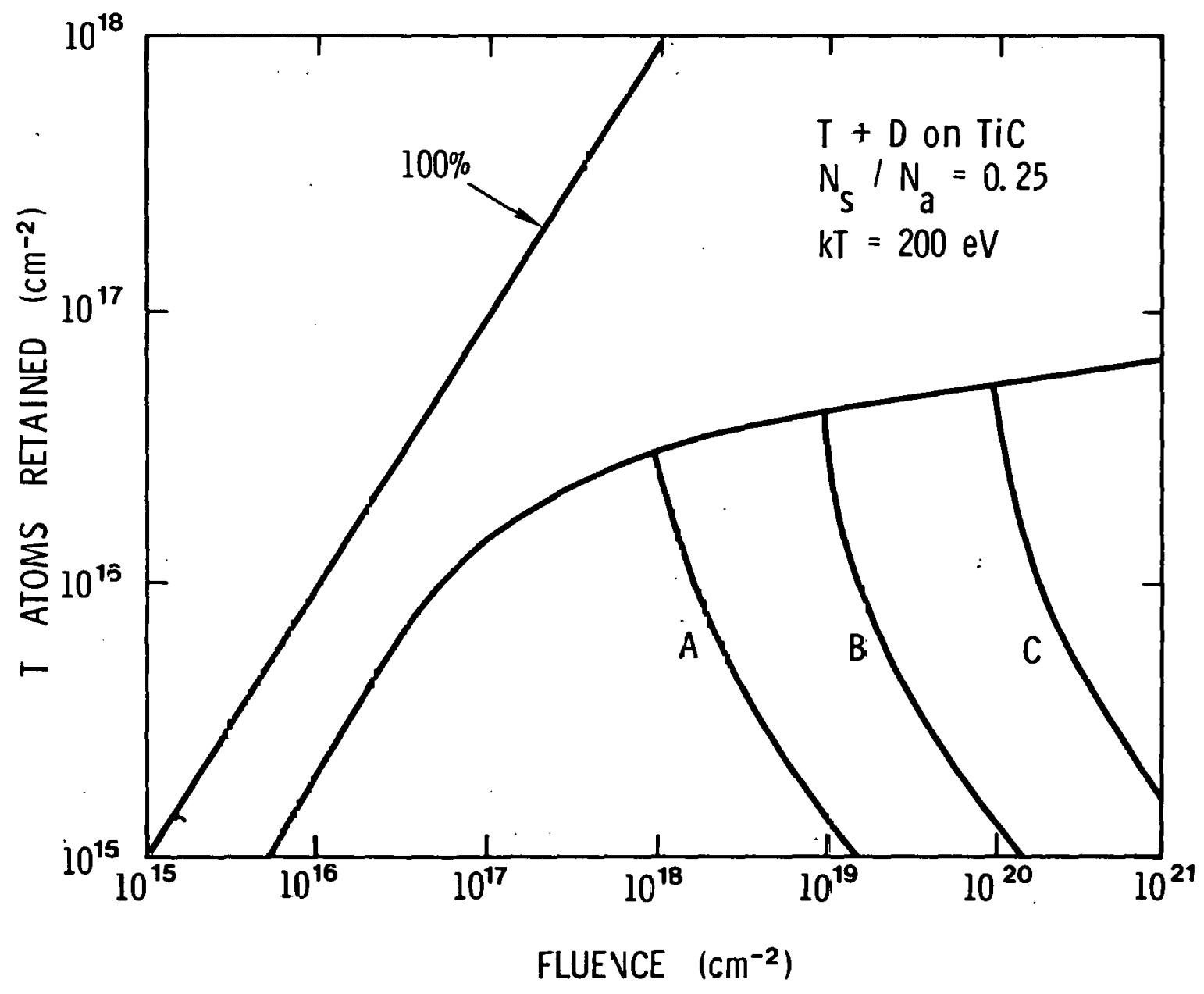




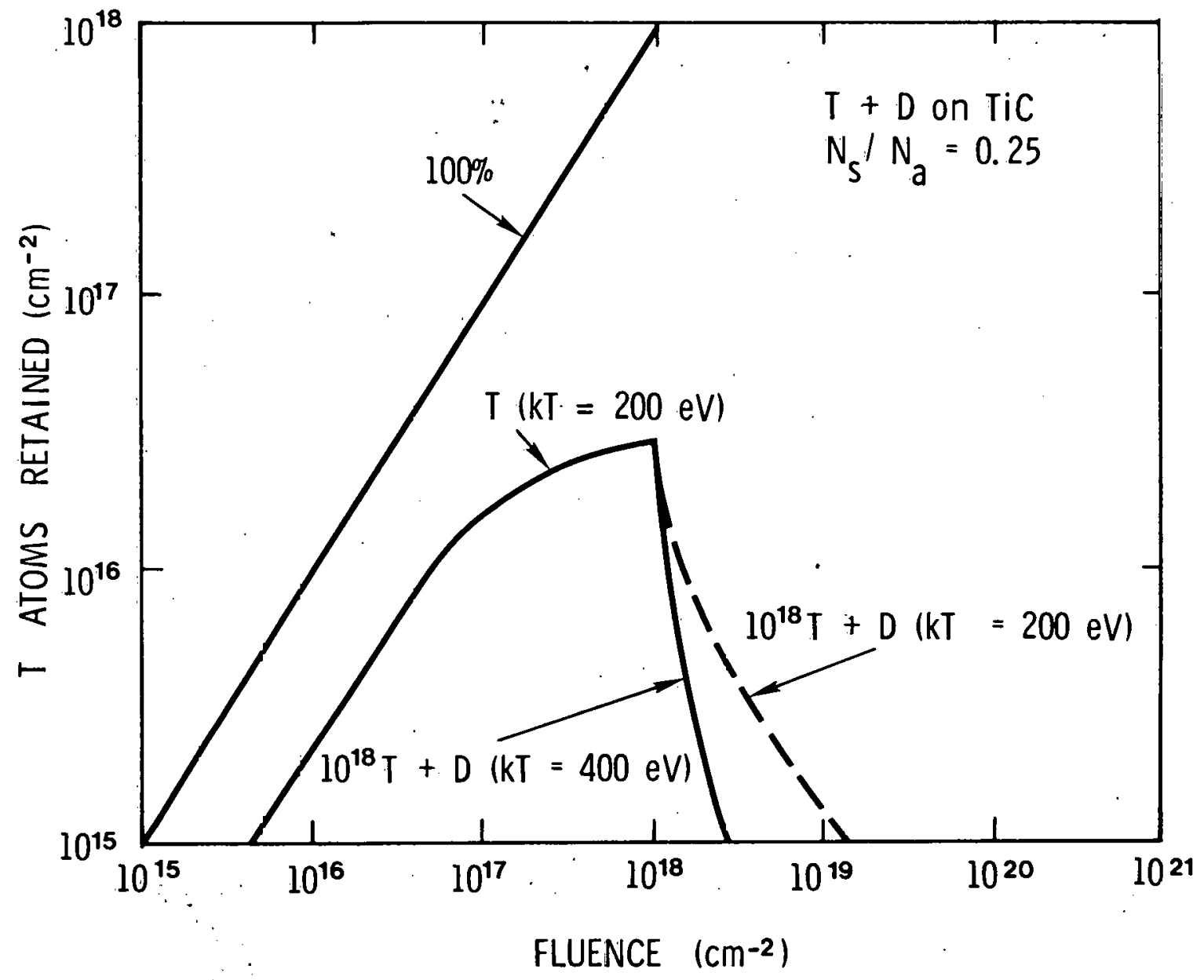


Distribution:

DOE/TIC - UC-20C (195)

K. Burrell

General Atomic Company

P. O. Box 81608

San Diego, CA 92138

R. P. Drake

Lawrence Livermore Laboratory

P. O. Box 808

Livermore, CA 94551

E. Marmar

Massachusctts Institute of 'l'echnology

77 Massachusetts Avenue

Cambridge, MA 02139

H. C. Howc

Oak Ridge National Laboratory

P. O. Box $\mathrm{X}$

Oak Ridge, TN 37830

J. R. Roberto .

Oak Ridge National Laboratory

P. O. Box X

Oak Ridge, TN 37830

R. A. zuhr

Oak Ridge National Laboratory

P. O. Box X

Oak Ridge, TN 37830

R. A. Tiangley

Oak Ridge National Laboratory P. O. Box X

Oak Ridge, TN 37830

J. Cecchi

Princeton Plasma Physics Lab.

Princeton University

P. O. Box 451

Princeton, NJ 08540

S. A. Cohen

Princeton Plasma Physics Tab.

Princeton University

P. O. Box 451

Princeton, NJ 08540

H. F. Dylla

Princeton Plasma Physics Lab.

Princeton University

P. O. Box 451

Princeton, NJ 08540

K. Owens

Princeton Plasma Physics Lab.

Princeton University

P. O. Box 451

Princeton, NJ 08540

R. Conn

University of CaliforniaLos Angeles

School of Enqineering, and Applied Science

Los Angeles, CA 90024

3141

5000

5100

5110

5111

5111

5111

5112

5830

5834

5834

5834

0400

8340

8347

8347

8347

8347

3151

C. A. Pepmueller (Actg) (5)

(Unlimited Release)
W. L. Garner (3)

For: DOE/TIC

J. I. Gall

F. L. Vook

Schwoebel

Picraux (20)

D. K. Brice $(20)$

W. R. Wampler $(20)$

B. L. Duyle (20)

M. J. Davis

D. M. Mattox

J. B. Whitley

A. W. Mullendore

R. S. Blewer

- Bauer

. Gauster

K. Wilson

A. E. Pontau

R. D. Kerst

8266 E. A. Aas (2) 

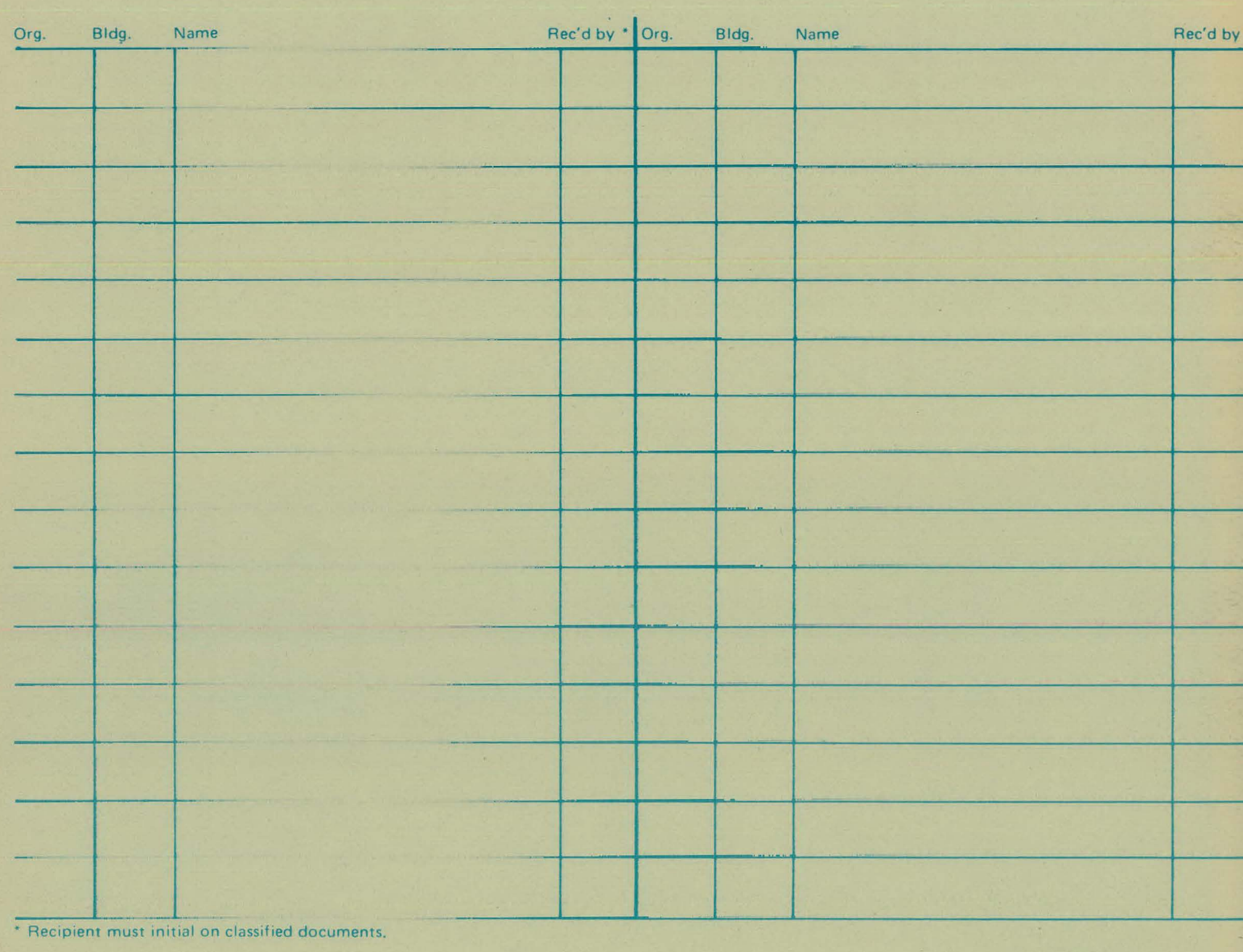